\title{
Responsabilidade Social nas Agroindústrias Canavieiras no Brasil ${ }^{1}$
}

\author{
Martin Airton Wissmann², Pery Francisco Assis Shikida ${ }^{3}$ e \\ Juan Carlos Ayala ${ }^{4}$
}

Resumo: O objetivo desta pesquisa é identificar qual das dimensões econômica, ambiental ou social exerce maior influência no comportamento socialmente responsável das agroindústrias canavieiras no Brasil. Para isso, foi realizado um levantamento teórico a fim de identificar a origem, evolução e conceituação da Responsabilidade Social, além de caracterizar e apresentar a relação das agroindústrias canavieiras com o tema de pesquisa. Este trabalho adotou como procedimento metodológico as pesquisas de natureza explicativa e quantitativa. Como instrumento de pesquisa aplicou-se um questionário, elaborado a partir do embasamento teórico e das orientações disponibilizadas pela Global Reporting Initiative, sendo aplicado a um universo de 184 agroindústrias canavieiras (individuais ou grupo de empresas), obtendo retorno de 128 questionários. Para a validação das hipóteses, foi utilizada a modelagem de equações estruturais, aplicada por meio do SmartPLS. Os resultados demonstraram que existe influência positiva das dimensões econômica, ambiental e social no CSR. Quando comparadas as três dimensões, devido ao fato de que a atividade sucroalcooleira é bastante sensível às questões ambientais, além das regulamentações que orientam os processos industriais, estatisticamente a dimensão ambiental mostrou-se não significante. Por outro lado, a dimensão social, por questões históricas, características da atividade e administrativa, mostrou maior poder de influência no CSR.

Palavras-chaves: Comportamento socialmente responsável, agroindústria canavieira, dimensões econômica, ambiental e social.

Abstract: The objective of this research is to identify which of the economic, environmental or social dimensions exerts greater influence on the socially responsible behavior of the sugarcane agroindustry in Brazil. In order to do that, a theoretical survey was carried out to identify the origin, evolution and conceptualization of Social Responsibility, besides characterizing and presenting the relationship of the sugarcane agroindustry with the research theme. This research adopted as

1. Data de submissão: 30 de março de 2017. Data de aceite: 26 de fevereiro de 2018.

2. Universidade Estadual do Oeste do Paraná - Unioeste, Toledo, Paraná, Brasil. E-mail: martin.wissmann@unioeste.br

3. Universidade Estadual do Oeste do Paraná - Unioeste, Toledo, Paraná, Brasil. Bolsista de Produtividade em Pesquisa do CNPq. E-mail: pery.shikida@unioeste.br

4. Universidade de La Rioja, Logroño, Rioja, Espanha. E-mail: juan-carlos.ayala@unirioja.es 
methodological procedure explanatory and quantitative research. As a research instrument, a questionnaire was applied, based on the theoretical basis and guidelines provided by the Global Reporting Initiative, applied to a universe of 184 sugarcane agroindustry (individual or group of companies), obtaining a return of 128 questionnaires. In order to attest the hypothesis, the structural equation modeling, applied through the SmartPLS, was used. The results demonstrate there is a positive influence of the economic, environmental and social dimensions in the CSR. When comparing the three dimensions, due to the fact that sugar-alcohol activity is very sensitive to environmental issues, in addition to the regulations that guide industrial processes, statistically the environmental dimension was not significant. On the other hand, the social dimension, due to historical, activity and administrative characteristics, exerts major influence in CSR.

Key-words: Socially responsible behavior, sugar cane industry, economic, environmental and social dimensions.

Classificação JEL: M14, Q13.

DOI: http://dx.doi.org/10.1590/1234-56781806-94790560408

\section{Introdução}

As relações comerciais vêm passando por importantes mudanças nos últimos anos. Além de preço e qualidade, outros fatores como impactos econômico, ambiental e social, por exemplo, passaram a receber mais importância tanto por parte da legislação, que regula as diversas atividades, como pelo consumidor, no momento de definir a preferência por um produto. Diante dessas mudanças, as empresas passaram a adotar estratégias administrativas no intuito de atender às expectativas do público interessado (stakeholders), enfatizando a qualidade de vida e o bem-estar do público interno da empresa, buscando a mitigação dos impactos negativos de sua atividade na comunidade e no meio ambiente. Este comportamento, embora possa ser composto por uma diversidade maior e mais abrangente de ações, é comumente denominado de Responsabilidade Social (SILVA e GARCIA, 2011; EON, 2015).

Vários fatos históricos marcaram o surgimento desse comportamento, dos quais podem ser citados alguns: como principal fato teórico o livro $O$ evangelho da riqueza de Andrew Carniegie; no ambiente político a "ideia de função social da propriedade", apresentada na constituição de Weimar (Alemanha); como período econômico o século XX (até 1950), o qual foi marcado pela transição da economia agrícola para a industrial, pelas mudanças no processo produtivo derivado da evolução tecnológica e da aplicação da ciência na organização do trabalho (STONER e FREEMAN, 1990;
TENÓRIO, 2006). No entanto, o que se observa é que não há um consenso entre os pesquisadores quanto ao período exato do surgimento deste comportamento.

$\mathrm{O}$ processo evolutivo gerou diversas vertentes conceituais que, em síntese, remetem ao entendimento de que a Responsabilidade Social é um conjunto de ações e valores que visam integrar interesses corporativos, sociais e ambientais (dimensões econômica, social e ambiental) no sentido de preservá-los, buscando uma sociedade mais justa, ética e com qualidade de vida. Passou de simples atendimento às exigências legais e da sociedade, para um comportamento que cumpre com as obrigações impostas, e que vai além, promovendo ações voluntárias em prol da sociedade e do meio ambiente (ETHOS, 2000; MARIANO, 2000; ASHLEY, 2002; KARKOTLI, 2007; DIAS, 2012; ETHOS, 2013; EON, 2015).

Um setor que é bastante sensível às questões sociais e ambientais e que vem promovendo ações relacionadas à Responsabilidade Social é o sucroalcooleiro e/ou sucroenergético. As agroindústrias canavieiras assumem a função de industrialização neste setor, e exercem um significativo papel na economia brasileira com a absorção de mão de obra, arrecadação de tributos, segurança alimentar, produção de combustível renovável, cogeração de energia elétrica, entre outros. Por outro lado, também podem gerar impactos negativos no saneamento e sistema de saúde dos municípios, por meio da concentração fundiária, geração de desemprego do cortador de cana, recrudescendo o êxodo rural com a mecanização da colheita, entre outros (SHIKIDA e SOUZA, 2009). 
Diante desse cenário, algumas agroindústrias canavieiras passaram a adotar uma postura vinculada ao Comportamento Socialmente Responsável(CSR), porém, percebe-se que o desenvolvimento da Responsabilidade Social não se encontra no mesmo estágio. O que se observa é que o setor sucroalcooleiro apresentou avanços em termos de produtividade e na ampliação do mercado; no entanto, o mesmo não ocorreu, de forma proporcional, em relação ao CSR (VERDOLIN e ALVES, 2005; RODRIGUES e ORTIZ, 2006).

Conforme estudo realizado por Carvalho, Vian e Braun (2011), a maioria das agroindústrias canavieiras está no estágio estratégia empresarial, enquanto outras são classificadas no estágio filantropia. As empresas estão confundindo filantropia com Responsabilidade Social; porém, as ações de sustentabilidade estão em constante evolução. Observa-se que não há uma clara definição dos benefícios, o estágio evolutivo apresenta-se de forma heterogênea e as dimensões econômica, ambiental e social recebem importância diferenciada ou não são ponderadas nas tentativas de adoção do CSR.

Desta forma, observa-se que as agroindústrias canavieiras promovem impactos econômicos, ambientais e sociais, que a Responsabilidade Social está contemplada nas estratégias de gestão, porém, apresenta estágio diferenciado na sua adoção, e que não há ponderação a fim de atribuir maior ou menor grau de importância nas ações promovidas. Diante desse cenário, este estudo norteia-se pela busca de resposta sobre qual das dimensões (econômica, ambiental ou social) exerce maior influência no CSR das agroindústrias canavieiras no Brasil.

Para obter resposta para esta problemática, a pesquisa buscou descrever a origem e a conceituação da Responsabilidade Social, contextualizar a agroindústria canavieira e seus impactos econômico, ambiental e social e analisar a influência destas dimensões no CSR, mediante a aplicação da Modelagem de Equações Estruturais (MEE).

\section{Responsabilidade social e sua relação com a agroindústria canavieira}

Existem alguns momentos que podem ser citados como possíveis marcos do surgimento da Responsabilidade Social. Como um importante fato teórico, citado por Stoner e Freeman (1990), ocorrido em 1899, destaca-se a publicação do livro "O Evangelho da Riqueza", de Andrew Carnegie, o qual, por meio de uma abordagem clássica, caracterizou um possível comportamento das grandes empresas em relação à Responsabilidade Social.

Além desse, outros fatos marcaram a trajetória histórica de desenvolvimento da Responsabilidade Social pelo mundo. O Instituto Ethos (2001) apresentou esta trajetória, de 1929 a 2000, com alguns fatos importantes, dos quais se destacam a Constituição de Weimar (Alemanha) que inaugura a ideia de função social da propriedade em 1929; o surgimento dos movimentos pela Responsabilidade Social nos Estados Unidos na década de 1960; a Fides (Fundação Instituto de Desenvolvimento Empresarial e Social) e a ADCE (Associação de Dirigentes Cristãos de Empresas) passam a estudar o tema Responsabilidade Social a partir de 1976; a criação, em 1990, nos Estados Unidos, do Domini 400 Social Index - um dos primeiros índices de empresas socialmente responsáveis; a elaboração da SA8000 - norma de certificação voltada para as condições de trabalho; o surgimento da Dow Jones Sustainability Index (DJSI) em 1999; a 1a versão dos Indicadores Ethos de RSE e o Global Compact da ONU em 2000.

Atualmente, o que se tem observado é que a cultura da Responsabilidade Social está presente nas organizações, sendo possível constatar avanços em suas práticas, aprimoramento no relacionamento com os funcionários, adoção de estratégias visando a redução do impacto ambiental e investimentos no desenvolvimento das comunidades em que atuam. Atrelado aos seus avanços, estão os instrumentos propostos para orientar as empresas nesta gestão responsável, desde macrossinalizadores, como a Agenda 21 (ECO - 92), até sistemas de gestão compostos por normas padronizadas, tais como a SA 8000, AccountAbility - AA 1000, OHSAS 18000, entre outras (CARVALHO et al., 2009).

A partir desta evolução surgem os aspectos conceituais da Responsabilidade Social que, de acordo com Mariano (2000), significa a representação do compromisso da administração quando estabelece diretriz, toma decisões e promove ações que são importantes em termos de valores e objetivos da sociedade. De forma complementar, Ashley (2002) diz que se trata de um compromisso que a organização deve ter com a sociedade, o qual se expressa por meio de atos e 
atitudes com reflexos positivos de modo amplo, e para alguma comunidade de modo específico, atingindo proativamente e coerentemente o seu papel na sociedade. Em relação aos gastos com atos e atitudes, Fontes (2001) defende que estes devem ser vistos como investimento, sobretudo quando estiverem vinculados à promoção do desenvolvimento humano.

Com isso, a organização assume obrigações de caráter moral que transcendem os estabelecidos em lei, ainda que não estejam vinculados à sua atividade, mas que possam contribuir para o desenvolvimento sustentável dos povos. Em uma visão geral, a Responsabilidade Social é toda e qualquer ação que possa contribuir para a melhoria da qualidade de vida da sociedade, o que possibilita às organizações demonstrar o seu comprometimento por meio dos projetos sociais desenvolvidos (KARKOTLI, 2007).

Para Dias (2012), a Responsabilidade Social se coloca como um instrumento positivo, tanto para as empresas quanto para a sociedade, tornando-se importante ferramenta para identificar, prevenir e corrigir as consequências indesejadas que acompanham as atividades empresariais e sua repercussão na organização do espaço urbano das cidades. Isso requer um comportamento ético e responsável que as empresas devem assumir voluntariamente, tornando-se responsáveis pelos impactos gerados pela sua atuação, indo além do que obriga a legislação, e além de suas responsabilidades econômicas.

Corroborando esse pensamento, de acordo com Holme e Watts (1999), a Responsabilidade Social resulta de um compromisso contínuo das empresas com o comportamento ético que contribui para o desenvolvimento econômico, melhorando a qualidade de vida dos empregados e de suas famílias, bem como da comunidade local e da sociedade em geral.

A partir desse comportamento, a empresa passa a desenvolver um conjunto de ações vinculadas aos aspectos econômicos, sociais e ambientais, que, quando isolados e sem parâmetros definidos para sua identificação e mensuração, torna-os difíceis de serem analisados. Por outro lado, quando estes são claramente identificados e, quando possível, mensurados, proporcionarão maior facilidade de análise do CSR de uma empresa.

Estas ações são comumente evidenciadas por meio de relatórios de sustentabilidade ou demonstrativos sociais que, embora existam vários modelos sugeridos, para Avram e Avasilcai (2014), os mais importantes (não refletida pela ordem com que estão apresentados) são o Global Environmental Management Initiative (GEMI), Resource Based View (RBV) e o Global Reporting Inatiative (GRI).

$\mathrm{O}$ modelo mais difundido e que tem o maior reconhecimento mundial é o GRI. Trata-se de um relatório de sustentabilidade sugerido pela Global Reporting Initiative, organização não governamental que foi criada em 1997 como uma iniciativa conjunta da Coalition for Environmentally Responsible Economies (Ceres), e do Programa das Nações Unidas para o Meio Ambiente (PNUMA). Atualmente, com sede em Amsterdã (Holanda), conta com os representantes regionais, identificados como Focal Points, em sete países e uma rede mundial de 30.000 pessoas. Tem como objetivo melhorar a qualidade, o rigor e a aplicabilidade dos relatórios de sustentabilidade. Esta iniciativa tem recebido apoio e participação de indústrias dos diversos setores de atividade, grupos ativistas sem fins lucrativos, órgãos contábeis, organizações de investidores e sindicatos, entre outros. Portanto, trata-se de uma organização formada por especialistas de vários países, trabalhando conjuntamente para atingir um consenso sobre as diretrizes para relatórios que possam alcançar aceitação mundial (MARQUES e ALLEDI FILHO, 2012; GRI, 2015a).

Visando atender à missão, que consiste em criar condições para que a prática de relatórios de sustentabilidade se torne padrão, a GRI passou a elaborar diretrizes e, com isso, fornecer orientações e suporte para as organizações. A primeira versão das diretrizes, conhecida por G1, foi lançada em 2000. Novas versões foram desenvolvidas, sendo a segunda geração - G2 em 2002, a terceira geração - G3 em 2006, a qual, após sua atualização em 2011, recebeu a denominação de G3.1. Em maio de 2013, a GRI lançou a quarta geração de diretrizes, em vigor atualmente, conhecida como G4 (GRI, 2015b).

A geração G4 é composta de 150 indicadores sendo dividida em Conteúdos Padrão Gerais e Conteúdos Padrão Específicos. Os indicadores incluem Informações sobre a Forma de Gestão, sobre as ações vinculadas às categorias Econômica, Ambiental e Social, esta última dividida em Práticas Trabalhistas e Trabalho Decente, Direitos Humanos, Sociedade e Responsabilidade pelo Produto (GRI, 2013b).

Por ser o modelo mais difundido e aceito mundialmente, o setor sucroalcooleiro passou a utilizá-lo em 
algumas publicações promovidas por entidades representativas de classe e pelas agroindústrias canavieiras, as quais, assim como outras atividades, promovem impactos econômicos, ambientais e sociais.

\subsection{Agroindústria canavieira e a responsabilidade social}

O desenvolvimento e importância da agroindústria canavieira frente à história econômica do Brasil, foi retratado por Szmrecsányi (1979) ao mencionar que, por quase dois séculos depois do descobrimento do Brasil, esta atividade foi praticamente o único pilar em que se apoiava a economia colonial.

Durante o período evolutivo, as agroindústrias canavieiras foram atingidas por várias intervenções; dentre elas destacam-se: a criação do Instituto do Açúcar e do Álcool (IAA), os incentivos à modernização tecnológica e à pesquisa, a implantação do Programa Nacional do Álcool (Proálcool) e o advento do carro flex-fuel (VIAN, 2003; RAMOS, 2008).

No âmbito de políticas públicas, destaca-se o lançamento, por parte do governo federal, de um programa para orientar a expansão sustentável da cana-de-açúcar no País. Este programa tem como base critérios ambientais, econômicos e sociais e é denominado de Zoneamento Agroecológico da Cana-de-Açúcar (ZAE Cana). Após estudo minucioso, foram estipuladas as áreas mais propícias ao plantio da cultura, considerando tipos de clima, solo, biomas, declividade do terreno, necessidade de irrigação, entre outras características (MAPA, 2015).

Estas inicitivas estão apoiadas no fato que a atividade sucroalcooleira normalmente está relacionada com possíveis impactos econômicos, ambientais e sociais.

Os impactos econômicos estão, principalmente, vinculados à absorção de mão de obra em grande quantidade, geração de divisas e arrecadação de tributos. Já em relação aos impactos ambientais, de acordo com Andrade e Diniz (2007), são promovidos pelas agroindústrias canavieiras na fase agrícola (redução da biodiversidade, contaminação da água por excesso de adubação química e uso de defensivos, contaminação do ar com as queimadas, danos à fauna e à flora com incêndios descontrolados; na fase industrial por meio do fluxo de massa (resíduos sólidos, líquidos e gasosos), poluição das águas, poluição do solo e poluição do ar, por outro lado, promovem a cogeração de energia, produzem um combustível renovável e com menor poder poluente, em relação aos combustíveis fósseis e estão reduzindo as queimadas migrando da colheita manual para a mecanizada.

Embora vários fatores possam caracterizar o impacto social exercido pelas agroindústrias canavieiras, o que fica, normalmente, mais evidente são os relacionados aos trabalhadores, sejam aqueles envolvidos no processo de extração da matéria-prima ou na sua industrialização. Mundo Neto (2009) destaca que o setor sucroalcooleiro enfrentou muitas críticas não só pelos impactos ambientais causados por suas atividades produtivas, mas também pelas condições de trabalho precárias, condições insalubres e formas de remuneração.

Não obstante, a redução do uso de mão de obra na colheita, o que tende a gerar um grande número de desempregados no setor, pode gerar um aumento da ocupação permanente da mão de obra local, derivada, justamente, da substituição da colheita manual pela mecânica; formação de cooperativas para a colheita mecânica; e investimentos em educação e treinamento especializado visando a qualificação de trabalhadores face à tecnificação progressiva do cultivo (MANZATTO et al., 2009).

Diante deste cenário, em que o tripé que sustenta o CSR (econômico, ambiental e social), é diretamente influenciado pelas agroindústrias canavieiras, percebe-se que, de forma geral, o setor sucroalcooleiro passou por etapas evolutivas; no entanto, ainda se configura em um objetivo a ser alcançado. É importante destacar que, desde 2000, houve conquistas no cenário internacional, pois, por ser o maior produtor mundial de açúcar e etanol, a partir da cana-de-açúcar, passou-se a exigir uma nova postura das usinas que integram a atividade canavieira no Brasil. As exigências se voltaram à necessidade de disponibilizar produtos de alta qualidade, livres de agrotóxicos, e obtidos sob condições consideradas socialmente aceitáveis pela opinião pública internacional (BRAGATO et al., 2009).

No intuito de cumprir com uma agenda mínima, frente ao que pode ser considerado CSR, em 2006, a União da Indústria de Cana-de-açúcar (Unica), maior organização representativa do setor sucroalcooleiro no Brasil, firmou parceria com o Instituto Ethos visando a implementação dos Indicadores Ethos de Responsabilidade Sócio Empresarial. Em 2008, foi 
divulgado o primeiro relatório socioambiental do setor sucroenergético brasileiro (NOVAES, 2009).

No entanto, ainda que algumas agroindústrias canavieiras e até mesmo a maior entidade que representa o setor tenham promovido iniciativas visando a divulgação de ações de Responsabilidade Social, utilizando um modelo de relatório mundialmente reconhecido, ou simplesmente difundindo o comportamento e a relevância socioambiental das agroindústrias canavieiras em suas publicações, observa-se que não há uma constância nesse comportamento, exemplo disso é a reestruturação administrativa promovida pela Unica em 2013, que teve o departamento de Responsabilidade Social suprimido (WISSMANN, 2017).

\section{Metodologia}

Como procedimento metodológico o estudo utilizou a pesquisa explicativa no intuito de identificar os fatores que influenciam e determinam a ocorrência da Responsabilidade Social nas agroindústrias canavieiras, explicando a razão deste comportamento.

O estudo também adotou como metodologia a pesquisa quantitativa a partir da aplicação da MEE, com base na coleta de dados promovida por meio de um questionário aplicado aos gestores das agroindústrias canavieiras instaladas no Brasil.

Quanto aos procedimentos, adotou-se a pesquisa bibliográfica e survey. A primeira tem sua aplicação no embasamento teórico no intuito de alcançar o adequado entendimento histórico e conceitual do tema e objeto em estudo; já a segunda resulta de um levantamento e tem o procedimento semelhante ao censo, diferenciando-se pelo fato de examinar uma amostra da população e não a sua totalidade (BABBIE, 1999; LAKATOS e MARCONI, 2001).

Para a coleta de dados, conforme prevê a pesquisa no modelo survey, foi utilizado o questionário (Apêndice A), o qual, de acordo com Chizzotti (2001), trata-se de um conjunto de questões pré-elaboradas. Neste estudo, o questionário foi composto por 25 questões [escala likert sendo: (1) sem importância; (2) pouco importante; (3) importante; (4) muito importante; (5) extremamente importante], sendo divididas em três dimensões (sete na dimensão econômica, oito na ambiental e dez na dimensão social) e 25 subquestões (com respostas binárias em relação à promoção ou não das ações socialmente responsáveis), todas elaboradas com base na revisão da literatura e na quarta geração (G4) das Diretrizes da GRI (2013a).

Para a aplicação do questionário, inicialmente foi realizado um contato telefônico, pelo qual foi identificado o respondente, considerando que este deveria conhecer intimamente a gestão da empresa, sobretudo as ações de Responsabilidade Social, quando desenvolvidas. A coleta das respostas se deu por meio de entrevista ou por meio de um formulário eletrônico.

Para definir a amostra partiu-se do universo composto por 373 agroindústrias canavieiras, obtido após consulta realizada em agosto de 2015 (data limite, pois empresas mais atuais não teriam tempo hábil para desenvolver o CSR), junto ao Mapa, com base no relatório fornecido pelo Sistema de Acompanhamento da Produção Canavieira (SAPCANA, 2015).

Após analisar o relatório, observou-se a necessidade de excluir duas empresas cadastradas em duplicidade e três que não atendiam às características inerentes às agroindústrias canavieiras. Além disso, foram identificadas, com base no relatório gerado por Novacana (2016a), 44 agroindústrias canavieiras que se encontravam em fase de recuperação judicial, as quais também foram excluídas do universo de pesquisa, diante das estimativas que demonstram que o tempo médio de um processo desse tipo varia de seis a dez anos e que apenas uma em cada 100 empresas consegue retornar à atividade normal após o processo de recuperação judicial (FILGUEIRAS, 2016; MARIANO, 2016).

Após a reclassificação do universo, restaram 324 empresas aptas à realização da pesquisa. Não obstante, o setor sucroalcooleiro, historicamente, é bastante dinâmico e, dentre as mudanças mais recentes, em relação à organização administrativa, tem-se observado a ocorrência de fusões e aquisiçóes que acontecem entre usinas ou grupos econômicos e a criação e aumento de tais grupos como uma estratégia de negócio no ambiente competitivo (CHAGAS, 2014).

Entendendo que a Responsabilidade Social pode ser caracterizada como um procedimento administrativo estratégico, com procedimentos adotados de forma semelhante para todas as empresas do grupo, o levantamento de dados de mais de uma empresa do mesmo grupo poderia enviesar os resultados da pesquisa. Diante desse fato, identificou-se a existência de 49 grupos e 135 individuais; portanto, concluindo que 
o universo de pesquisa é composto por 184 organizações, distribuídas em 22 Unidades Federativas, sendo a maior concentração em São Paulo $(36,4 \%)$, seguido de Minas Gerais (12\%), Goiás (9,8\%), Paraná, Alagoas e Pernambuco (os três com 6\%). Os demais estados apresentaram porcentagens inferiores a $5 \%$.

Entre os possíveis apoios teóricos para elaboração das hipóteses, partiu-se de um estudo realizado por Penedo (2011), que identificou que as informações divulgadas, vinculadas à Responsabilidade Social, seguem a conveniência da empresa; observa-se a diminuição da participação dos salários na folha de pagamento e aumento da discrepância entre o menor e maior salário; e não há a demonstração de interesse em ampliar os investimentos socioambientais.

Já para Bragato et al. (2009), as agroindústrias canavieiras agem de forma que o foco das ações sociais se concentre nas áreas educacional e ambiental, deslocando para uma posição secundária as ações relacionadas à cultura, ao esporte e à saúde. $\mathrm{O}$ número de projetos não está, necessariamente, relacionado ao porte das empresas.

De forma mais abrangente, de acordo com Ethos (2007), para facilitar o entendimento sobre a prática da Responsabilidade Social, as empresas devem atribuir atenção e avaliar o seu desempenho: i) econômico, demonstrando detalhadamente os seus impactos; ii) social, reunindo dados sobre o bem-estar dos empregados, assim como garantindo os seus direitos, proporcionando participação nos lucros, promovendo a difusão dos direitos humanos, entre outros; e iii) ambiental, promovendo a gestão de resíduos, efluentes ou emissões de gases, demonstrando e gerindo os possíveis impactos aos recursos naturais como água, solo, ar e biodiversidade. Diante disso, é possível afirmar que cada uma das dimensões exerce influência no CSR, e estas, para efeitos de aplicação do MEE, podem ser positivas ou negativas.

Embora tenham sido citados apenas três estudos, pois a intenção não é relacionar um grande número de informações neste momento, o que se pretende é demonstrar que, em maior ou menor proporção, as ações são desenvolvidas seguindo uma determinada classificação, pois observa-se que a atividade promove impactos econômicos, ambientais e sociais.

Por outro lado, embora seja possível inferir que as dimensões exercem influência, não há uma padronização ou determinação equilibrada nas ações que com- põem a Responsabilidade Social, ou seja, para qual dimensão será atribuída maior ou menor atenção e em que proporção influenciam o CSR.

Desta forma, tendo como objetivo identificar qual das dimensões exerce maior influência no CSR, foram elaboradas as seguintes hipóteses:

- $\mathrm{H}_{1}$ : A dimensão econômica influi positivamente o CSR das agroindústrias canavieiras.

- $\mathrm{H}_{2}$ : A dimensão ambiental influi positivamente o CSR das agroindústrias canavieiras.

- $\mathrm{H}_{3}$ : A dimensão social influi positivamente o CSR das agroindústrias canavieiras.

Não obstante, diante de questões historicamente relacionadas com a atividade sucroalcooleira, como a possível ocorrência de trabalho infantil, análogo a escravo, o impacto na saúde e qualidade de vida dos trabalhadores temporários, baixa remuneração, carência de organização sindical, condições precárias de moradia e alimentação, conforme estudos realizados por Alessi e Navarro (1997), Mundo Neto (2009) e Maciel et al. (2011), conclui-se que a dimensão que possivelmente possa exercer maior influência no CSR seja a social.

A partir dessa possível influência, elaborou-se a seguinte hipótese:

- $\mathrm{H}_{4}$ : A dimensão social influi direta e positivamente em maior proporção do que as dimensões ambiental e social no CSR das agroindústrias canavieiras.

Para promover os testes de hipóteses, utilizou-se a técnica estatística conhecida por Modelagem de Equações Estruturais (MEE) ou Structural Equation Modelling (SEM) que, de acordo com Collares (2011), é um termo que não designa uma técnica estatística específica, e sim uma série de técnicas e procedimentos utilizados em conjunto.

De acordo com Hair Junior et al. (2005b), a MEE é uma técnica que permite separar relações para cada conjunto de variáveis dependentes, fornecendo uma estimação apropriada e mais eficiente para uma série de equações de regressão múltipla separadas e estimadas simultaneamente. É caracterizada pelo modelo estrutural ou modelo de caminhos, que relaciona variáveis independentes com dependentes, as quais devem ser distinguidas com base na experiência prévia ou outras orientações que permitem ao presquisador esta 
distinção, e pelo modelo de mensuração que permite ao pesquisador usar diversas variáveis (indicadores) para uma única variável independente ou dependente.

Para promover a operacionalização das equações estruturais foi utilizado o software SmartPLS 2.0 comumente abreviado por PLS-SEM. O primeiro passo na utilização PLS-SEM envolve a criação de um modelo de caminho que liga variáveis e construtos com base na teoria e na lógica. Ao criar o modelo caminho é importante distinguir a localização dos construtos, assim como as relações entre eles. Os construtos são considerados exógenos ou endógenos. Construtos exógenos atuam como variáveis independentes e não têm uma seta apontando para eles. Construtos endógenos se explicam por outros construtos. Embora os construtos endógenos sejam normalmente considerados como variável dependente, dentro da relação também podem agir como variáveis independentes quando eles estão colocados entre dois construtos (HAIR JUNIOR et al., 2014a).

Para garantir a confiabilidade dos resultados observados a partir da aplicação da MEE, recomenda-se a análise em dois momentos: 1) análise de confiabilidade do modelo de mensuração, ou seja, da relação entre os indicadores e os construtos, a qual deve ocorrer a partir da apuração da validade convergente (representa o quanto cada construto explica a variância dos seus indicadores), da confiabilidade composta (é uma estimativa da consistência interna de um construto e da validade discriminante (compõe-se de uma medida que demonstra que um construto é único e capta fenômenos não representados por outros construtos do modelo; 2) análise de confiabilidade do modelo estrutural, a qual envolve a análise dos coeficientes de determinação da variância $R^{2}$ (indica o percentual de variância de uma variável latente que é explicada por outras variáveis latentes); a relevância preditiva $\mathrm{Q}^{2}$ (apurada a partir da técnica blinfolding, possibilita avaliar a qualidade da predição do modelo ou acurácia do modelo ajustado e tem como critério de adequação valores maiores que zero); e o tamanho do efeito $\mathrm{f}^{2}$ (apurado a partir técnica blinfolding, demonstra quanto cada construto é útil para o ajuste do modelo) (CHIN, 1998; CHURCHIL JUNIOR, 1999; HAIR JUNIOR et al., 2005b; MALHOTRA, 2008; HENSELER, RINGLE e SINKOVICS, 2009; HAIR, RINGLE e SARSTEDT, 2011; HAIR JUNIOR et al., 2013; HAIR JUNIOR et al., 2014a; HAIR JUNIOR et al., 2014b).
Após garantir a confiabilidade do modelo de mensuração e estrutural, procede-se à análise do Path Coefficients (Coeficientes de Caminho) e ao teste de hipóteses, bastando confrontar os valores dos coeficientes beta- $\beta$ (coeficientes de regressão padronizados), apresentados nas relações causais ocorridas entre os construtos exógenos e endógenos.

Para o teste de hipóteses, medidas por meio da significância das relações causais, utiliza-se a técnica bootstrapping, que tem como parâmetro de estimação a realização de $n$ simulações, através de reamostragens aleatórias (com substituição) a partir dos dados. Com base nessas simulações estima-se o modelo caminho várias vezes sob constelações de dados ligeiramente alterados (HAIR JUNIOR et al., 2013).

\section{Resultados e discussão}

A partir do embasamento teórico é possível observar que o setor sucroalcooleiro apresentou avanços na prática de ações vinculadas À Responsabilidade Social; porém, as agroindústrias canavieiras estão em estágios diferentes em se tratando de CSR, sendo que algumas confundem Responsabilidade Social com filantropia. Também demonstrou que as agroindústrias canavieiras estão preocupadas com a sustentabilidade de suas operações, buscando minimizar o impacto ambiental e as disparidades sociais, mas não analisam o grau de importância das ações, tampouco ponderam a sua influência no CSR.

Com base nessas constatações, o estudo foi desenvolvido a partir dos construtos que compuseram o diagrama de caminhos, os quais foram elaborados a partir do suporte teórico que aborda o tripé da Responsabilidade Social (econômico, ambiental e social), e que caracterizam o CSR.

A coleta de dados ocorreu com um retorno de 128 questionários considerados válidos, representando 96\% de margem de confiança e 5\% de margem de erro.

Para garantir a confiabilidade dos dados, apurou-se o coeficiente alpha de Cronbach, o qual apresentou o resultado de 0,839 , sendo considerado consistente.

Garantida a confiabilidade dos dados, iniciou-se o processo de identificação do modelo estrutural, sendo composto por construtos de $1^{\underline{a}}$ e $2^{\underline{a}}$ ordens. Destaca-se que, embora se observe um número reduzido de estudos desenvolvidos no Brasil, com base no que 
prevê a literatura, por exemplo Chin (1998), Morales (2011), Hair Junior et al. (2014b), Cassol et al. (2016), a MEE possibilita a composição deste tipo de modelo, sendo comum em países onde esta técnica está mais desenvolvida.

Para a composição dos construtos utilizou-se a Análise Fatorial Exploratória (AFE) de componentes principais. A aplicação se deu com base na estrutura pré-definida, composta por três dimensões: econômica (7 variáveis de EC01 a EC07), ambiental (08 variáveis de EN01 a EN08) e social (10 variáveis de SLA01 a SLA05; SHR06 a SHR07; SSO08 a SSO09; e SPR10). ${ }^{5}$

Para aplicação do AFE é necessário observar se a matriz de dados é passível de fatoração. Desta forma, apurou-se 0,609 na medida KMO de adequação de amostragem, devendo, de acordo com Fávero et al. (2009), apresentar valores iguais ou superiores a 0,60 ; $p=0,000$ no teste de esfericidade de Bartlett, sendo aceitos, conforme Tabachnick e Fidell (2001), níveis de significância $p<0,05$; a matriz anti-imagem apresentou resultados de 0,550 a 0,742 , todos superiores às demais correlações, portanto, adequados, pois para serem considerados válidos, de acordo com Hair Junior et al. (2005a), devem ser superiores a 0,50 na diagonal principal e baixos nos demais valores; e as comunalidades com EC06 = 0,404 e a demais variáveis com valores superiores a 0,5 . Em relação às comunalidades, embora boa parte das literaturas sugira que apenas variáveis com valores acima de 0,5 atendem os requisitos necessários, de acordo com Costello e Osborne (2005), nas ciências sociais é comum observar, e serem aceitas, comunalidades consideradas de baixa a moderada, ou seja, entre 0,4 e 0,7 .

Após rodar e validar os dados, observou-se a composição de três fatores com raízes características maiores que um (critério de Kaiser), conforme defende Fávero et al. (2009), e que condensam as informações contidas nas sete variáveis utilizadas na análise. Os resultados demonstram que os três fatores explicam 63,4\% da variância total das variáveis selecionadas, conforme demonstrado na Tabela 1.

A partir das variáveis classificadas pela análise de componentes principais, da carga fatorial e do percentual da variância total, procedeu-se, apoiado na revisão

5. Foram mantidas as abreviações sugeridas no manual GRI-G4, sendo: EC - Economic; EN - Environmental; SLA - Labor Practices and Decent Work; SHR - Human Rights; SSO - Society; SPR - Product Responsibility. da literatura, à denominação de cada um dos fatores, como pode ser observado no Quadro 1.

Os mesmos procedimentos foram aplicados aos dados que se referem à dimensão ambiental, no intuito de verificar a confiabilidade. Os resultados da primeira rotação dos dados demonstraram que a variável EN07 apresentou baixo valor de comunalidade, ou seja, abaixo de 0,4 , sendo excluída essa variável. Com a segunda rotação dos dados, a partir das sete variáveis mantidas, apurou-se um KMO de 0,791, esfericidade de Bartlett com $p=0,000$, a matriz anti-imagem com valores superiores a 0,50 na diagonal principal e as comunalidades com valores superiores a 0,40.

Após rodar e validar os dados, observou-se a composição de dois fatores com raízes características maiores que um, e que condensam as informações contidas nas sete variáveis utilizadas na análise. Os resultados demonstram que os dois fatores explicam $54,5 \%$ da variância total das variáveis selecionadas, conforme demonstrado na Tabela 2.

Com base nas variáveis classificadas pela análise de componentes principais, na carga fatorial e no percentual da variância total, procedeu-se, apoiado na revisão da literatura, à denominação de cada um dos fatores, como pode ser observado no Quadro 2.

Semelhante às demais dimensões, foram aplicados os procedimentos buscando verificar a confiabilidade da dimensão social. Os resultados da primeira rotação dos dados demonstraram que a variável SHR07 apresentou a medida de adequação da amostragem, identificada na diagonal principal da matriz anti-imagem, abaixo do desejável $(0,5)$, sendo excluída. Com a segunda rotação dos dados, a partir das nove variáveis mantidas, apurou-se um KMO de 0,755, esfericidade de Bartlett com $p=0,000$, a matriz anti-imagem com valores superiores a 0,50 na diagonal principal e as comunalidades com valores superiores a 0,40.

Após rodar os dados, observou-se a composição de três fatores com raízes características maiores que um e que condensam as informações contidas nas nove variáveis utilizadas na análise. Os resultados demonstram que os três fatores explicam $55,2 \%$ da variância total das variáveis selecionadas (Tabela 3).

A partir das variáveis classificadas pela análise de componentes principais, da carga fatorial e do percentual da variância total, procedeu-se, apoiado na revisão da literatura, à denominação de cada um dos fatores (Quadro 3). 
Tabela 1. Variância total explicada: Dimensão Econômica

\begin{tabular}{c|ccc|ccc|ccc}
\hline \multirow{2}{*}{ Componentes } & \multicolumn{3}{|c|}{ Valores próprios iniciais } & \multicolumn{3}{c|}{$\begin{array}{c}\text { Somas de extração de } \\
\text { carregamentos ao quadrado }\end{array}$} & \multicolumn{2}{c}{$\begin{array}{c}\text { Somas rotativas de } \\
\text { carregamentos ao quadrado }\end{array}$} \\
\cline { 2 - 10 } & Total & $\begin{array}{c}\text { \% de } \\
\text { variância }\end{array}$ & \% cumulativa & Total & $\begin{array}{c}\% \text { de } \\
\text { variância }\end{array}$ & \% cumulativa & Total & $\begin{array}{c}\% \text { de } \\
\text { variância }\end{array}$ & $\%$ cumulativa \\
\hline 1 & 2,109 & 30,124 & 30,124 & 2,109 & 30,124 & 30,124 & 1,554 & 22,203 & 22,203 \\
2 & 1,214 & 17,349 & 47,473 & 1,214 & 17,349 & 47,473 & 1,464 & 20,914 & 43,116 \\
3 & 1,115 & 15,928 & 63,400 & 1,115 & 15,928 & 63,400 & 1,420 & 20,284 & 63,400 \\
\hline
\end{tabular}

Fonte: Elaboração própria.

Quadro 1. Denominação dos fatores a partir da Matriz Fatorial Rotacionada: EC

\begin{tabular}{|c|c|c|}
\hline Dimensão econômica & Denominação & Revisão da literatura \\
\hline $\begin{array}{l}\text { EC04 - Promover investimentos, com recursos próprios, em } \\
\text { infraestrutura e/ou serviços oferecidos, que beneficiam a socie- } \\
\text { dade. }\end{array}$ & \multirow{2}{*}{$\begin{array}{l}\text { O Fator } 1 \text { explica } 22,20 \% \text { da variância total e contém } \\
\text { itens relacionados com a dimensão econômica, a par- } \\
\text { tir da realização de ações que beneficiam a sociedade, } \\
\text { vinculadas à infraestrutura e/ou serviços e à educa- } \\
\text { ção. Este construto será denominado de: Investimen- } \\
\text { tos Econômicos para Sociedade (IES) }\end{array}$} & \multirow{2}{*}{$\begin{array}{l}\text { Verdolin e Alves (2005), } \\
\text { Manzatto et al. (2009), } \\
\text { Shikida e Souza (2009) }\end{array}$} \\
\hline $\begin{array}{l}\text { EC05 - Destinar recursos financeiros no intuito de promover } \\
\text { ações que geram impacto econômico indireto como: ações que } \\
\text { visem auxiliar pessoas de baixa renda, estímulo à implantação de } \\
\text { instituições de ensino (investimentos em educação), entre outros. }\end{array}$ & & \\
\hline $\begin{array}{l}\text { EC03 - Destinar recursos financeiros e/ou materiais, por parte } \\
\text { da empresa (de forma voluntária, além das obrigações legais), } \\
\text { visando evitar e/ou reduzir possíveis impactos ambientais (Ex.: } \\
\text { poluição, reciclagem e reutilização, outros). }\end{array}$ & \multirow{3}{*}{$\begin{array}{l}\text { O Fator } 2 \text { explica } 20,91 \% \text { da variância total e contém } \\
\text { itens relacionados com a dimensão econômica a par- } \\
\text { tir da realização de ações vinculadas aos recursos } \\
\text { tecnológicos visando a redução do impacto ambien- } \\
\text { tal (colheita mecanizada, reciclagem, reutilização de } \\
\text { matérias), e melhora nas condições de trabalho dos } \\
\text { empregados. Este construto será denominado de: In- } \\
\text { vestimentos Econômicos em Tecnologia (IET) }\end{array}$} & \multirow[t]{3}{*}{$\begin{array}{l}\text { Macedo (2005), } \\
\text { Rodrigues e Ortiz (2006), } \\
\text { Manzatto et al. (2009), } \\
\text { Chaddad (2010) }\end{array}$} \\
\hline $\begin{array}{l}\text { EC06 - Promover investimentos em tecnologias (automação, } \\
\text { ergonomia, equipamentos de proteção individual, outra), vi- } \\
\text { sando melhorar as condições de trabalho dos empregados. }\end{array}$ & & \\
\hline $\begin{array}{l}\text { EC07 - Promover investimento visando à colheita mecanizada } \\
\text { de cana-de-açúcar. }\end{array}$ & & \\
\hline $\begin{array}{l}\text { EC01 - Proporcionar aos empregados o recebimento de valores } \\
\text { referente à Participação nos Lucros e Resultados (PLR). }\end{array}$ & \multirow{2}{*}{$\begin{array}{l}\text { O Fator } 3 \text { explica } 20,28 \% \text { da variância total e contém } \\
\text { itens relacionados com a dimensão econômica, os } \\
\text { quais possibilitam aos empregados a participação } \\
\text { nos lucros e resultados da empresa e a participação } \\
\text { (parcial ou integral) em plano de aposentadoria. Este } \\
\text { construto será denominado de: Investimentos Econô- } \\
\text { micos em Pessoal (IEP) }\end{array}$} & \multirow{2}{*}{$\begin{array}{l}\text { Verdolin e Alves (2005), } \\
\text { Grajew (2006), Shikida e } \\
\text { Souza (2009), Manzatto et } \\
\text { al. (2009) }\end{array}$} \\
\hline $\begin{array}{l}\text { EC02 - Coparticipar ou promover o pagamento integral por } \\
\text { parte da empresa, de plano de aposentadoria complementar } \\
\text { aos empregados. }\end{array}$ & & \\
\hline
\end{tabular}

Fonte: Elaboração própria.

Tabela 2. Variância total explicada: Dimensão Ambiental

\begin{tabular}{c|ccc|ccc|ccc}
\hline \multirow{2}{*}{ Componentes } & \multicolumn{3}{|c|}{ Valores próprios iniciais } & \multicolumn{3}{c|}{$\begin{array}{c}\text { Somas de extração de } \\
\text { carregamentos ao quadrado }\end{array}$} & \multicolumn{2}{c}{$\begin{array}{c}\text { Somas rotativas de } \\
\text { carregamentos ao quadrado }\end{array}$} \\
\cline { 2 - 10 } & Total & $\begin{array}{c}\% \text { de de } \\
\text { variância }\end{array}$ & $\%$ cumulativa & Total & $\begin{array}{c}\% \text { de } \\
\text { variância }\end{array}$ & $\%$ cumulativa & Total & $\begin{array}{c}\% \text { de } \\
\text { variância }\end{array}$ & $\%$ cumulativa \\
\hline 1 & 2,725 & 38,927 & 38,927 & 2,725 & 38,927 & 38,927 & 2,440 & 34,860 & 34,860 \\
2 & 1,093 & 15,615 & 54,542 & 1,093 & 15,615 & 54,542 & 1,378 & 19,682 & 54,542 \\
\hline
\end{tabular}

Fonte: Elaboração própria.

Quadro 2. Denominação dos fatores a partir da Matriz Fatorial Rotacionada: EN

\begin{tabular}{|c|c|c|}
\hline Dimensão ambiental & Denominação & Revisão da literatura \\
\hline $\begin{array}{l}\text { EN01 - Possuir controle do uso de materiais renováveis e não } \\
\text { renováveis ou provenientes de reciclagem. }\end{array}$ & \multirow{5}{*}{$\begin{array}{l}\text { O Fator } 1 \text { explica } 34,86 \% \text { da variância total e contém } \\
\text { itens relacionados com a dimensão ambiental a partir } \\
\text { da realização de ações vinculadas ao controle do uso } \\
\text { de materiais, ao sistema de cogeração de energia, reu- } \\
\text { tilização de recursos naturais, áreas de proteção am- } \\
\text { biental e redução da emissão de gases poluentes. Este } \\
\text { construto refere-se às ações relacionadas à atividade } \\
\text { interna da empresa e será denominado de: Investi- } \\
\text { mentos Ambientais Internos (IAI) }\end{array}$} & \multirow{5}{*}{$\begin{array}{l}\text { Elia Neto (2005), Verdolin } \\
\text { e Alves (2005), Grajew } \\
\text { (2006), Manzatto et al. } \\
\text { (2009), Chaddad (2010) }\end{array}$} \\
\hline EN02 - Adotar sistema de cogeração de energia. & & \\
\hline $\begin{array}{l}\text { EN03 - Fazer uso, na atividade da empresa, de água reciclada } \\
\text { ou reutilizada. }\end{array}$ & & \\
\hline EN04 - Possuir áreas de proteção ambiental ou reflorestamento. & & \\
\hline $\begin{array}{l}\text { EN05 - Desenvolver ações que visem à redução da emissão de } \\
\text { gases poluentes no processo de industrialização. }\end{array}$ & & \\
\hline
\end{tabular}


EN06 - Acomodar e destinar os resíduos gerados pelo processo de industrialização (vinhaça, torta de filtro e outros), de forma a minimizar os impactos ambientais negativos.

EN08 - Possuir um setor responsável para receber e dar encaminhamento às queixas e reclamações relacionadas aos possíveis impactos ambientais causados pela empresa.

\begin{tabular}{|l|l|} 
O Fator 2 explica 19,68\% da variância total e contém & Macedo (2005), Toneto \\
itens relacionados com a dimensão ambiental a partir & Junior e Liboni (2008), \\
da realização de ações vinculadas à deposição e ao & Bragato et al. (2009), \\
destino de resíduos da industrialização, e designação & Junqueira, Sterchile e \\
de setor para receber e dar encaminhamento às quei- & Shikida (2009), Manzatto \\
xas e reclamações relacionadas aos impactos ambien- & et al. (2009), Augusto, \\
tais. Este construto será denominado de: Investimen- & Takahashi e Sachuk \\
tos Ambientais Externos (IAE) & $(2012)$
\end{tabular}

Fonte: Elaboração própria

Tabela 3. Variância total explicada: Dimensão Social

\begin{tabular}{|c|c|c|c|c|c|c|c|c|c|}
\hline \multirow{2}{*}{ Componentes } & \multicolumn{3}{|c|}{ Valores próprios iniciais } & \multicolumn{3}{|c|}{$\begin{array}{l}\text { Somas de extração de } \\
\text { carregamentos ao quadrado }\end{array}$} & \multicolumn{3}{|c|}{$\begin{array}{l}\text { Somas rotativas de } \\
\text { carregamentos ao quadrado }\end{array}$} \\
\hline & Total & $\begin{array}{l}\% \text { de } \\
\text { variância }\end{array}$ & \% cumulativa & Total & $\begin{array}{c}\% \text { de } \\
\text { variância }\end{array}$ & $\%$ cumulativa & Total & $\begin{array}{c}\text { \% de } \\
\text { variância }\end{array}$ & $\%$ cumulativa \\
\hline 1 & 2,829 & 31,434 & 31,434 & 2,829 & 31,434 & 31,434 & 1,796 & 19,953 & 19,953 \\
\hline 2 & 1,134 & 12,604 & 44,038 & 1,134 & 12,604 & 44,038 & 1,711 & 19,015 & 38,968 \\
\hline 3 & 1,008 & 11,199 & 55,237 & 1,008 & 11,199 & 55,237 & 1,464 & 16,270 & 55,237 \\
\hline
\end{tabular}

Fonte: Elaboração própria.

Quadro 3. Denominação dos fatores a partir da Matriz Fatorial Rotacionada: SO

\begin{tabular}{|c|c|c|}
\hline Dimensão social & Denominação & Revisão da literatura \\
\hline $\begin{array}{l}\text { SLA05 - Promover acompanhamento das práticas trabalhistas } \\
\text { adotadas pelos FORNECEDORES. }\end{array}$ & \multirow{4}{*}{$\begin{array}{l}\text { O Fator } 1 \text { explica } 19,95 \% \text { da variância total e contém } \\
\text { itens relacionados com a dimensão social a partir da } \\
\text { realização de ações vinculadas ao comportamento dos } \\
\text { fornecedores frente às práticas trabalhistas e benefí- } \\
\text { cios à sociedade, liberdade de os empregados parti- } \\
\text { ciparem de associações de classe e a disponibilização } \\
\text { de canais de comunicação com clientes e a sociedade. } \\
\text { Este construto é formado por ações que demonstram } \\
\text { as relações a montante e a jusante na cadeia de rela- } \\
\text { cionamento e será denominada de: Ações Sociais na } \\
\text { Cadeia de Suprimento (ASCS) }\end{array}$} & \multirow{4}{*}{$\begin{array}{l}\text { Elia Neto (2005), Macedo } \\
\text { (2005), Grajew (2006), } \\
\text { Andrade e Diniz (2007), } \\
\text { Manzatto et al. (2009) }\end{array}$} \\
\hline $\begin{array}{l}\text { SHR06 - Dar liberdade aos empregados para participarem de } \\
\text { associações de entidades de classe, reconhecendo sua função } \\
\text { (Ex.: Sindicatos). }\end{array}$ & & \\
\hline $\begin{array}{l}\text { SSO09 - Verificar na seleção de fornecedores se estes promovem } \\
\text { ações socialmente responsáveis em benefício da sociedade. }\end{array}$ & & \\
\hline $\begin{array}{l}\text { SPR10 - Possuir um canal de comunicação pelo qual disponibi- } \\
\text { liza informações/orientações para a sociedade/clientes, sobre os } \\
\text { produtos que comercializa e/ou as atividades que desenvolve. }\end{array}$ & & \\
\hline $\begin{array}{l}\text { SLA01 - Promover ações para evitar a rotatividade (turnover) de } \\
\text { empregados, dentro e/ou fora do ambiente de trabalho. }\end{array}$ & \multirow{3}{*}{$\begin{array}{l}\text { O Fator } 2 \text { explica } 19,02 \% \text { da variância total e contém } \\
\text { itens relacionados com a dimensão social a partir da } \\
\text { realização de ações vinculadas à redução do turnover, } \\
\text { adoção da igualdade na definição de cargos e salários } \\
\text { e evitar e combater a corrupção. Este construto é com- } \\
\text { posto de ações que demonstram a preocupação com a } \\
\text { manutenção dos empregados, evitando a discrimina- } \\
\text { ção e a corrupção. Será denominado de: Ações Sociais } \\
\text { de Valorização e Antidiscriminação (ASVA) }\end{array}$} & \multirow{3}{*}{$\begin{array}{l}\text { Verdolin e Alves (2005), } \\
\text { Andrade e Diniz (2007), } \\
\text { Balsadi (2007) }\end{array}$} \\
\hline $\begin{array}{l}\text { SLA04 - Adotar critérios de igualdade em relação à etnia, idade } \\
\text { ou gênero na definição de salários e/ou cargos de chefia. }\end{array}$ & & \\
\hline $\begin{array}{l}\text { SSO08 - Adotar procedimentos para evitar e combater a cor- } \\
\text { rupção nas atividades que a empresa está envolvida. }\end{array}$ & & \\
\hline $\begin{array}{l}\text { SLA02 - Adotar ações evitando riscos de acidentes e de doenças } \\
\text { relacionadas à ocupação dos empregados. }\end{array}$ & \multirow{2}{*}{$\begin{array}{l}\text { O Fator } 3 \text { explica } 16,27 \% \text { da variância total e contém } \\
\text { itens relacionados com a dimensão social a partir da } \\
\text { realização de ações direcionadas ao treinamento, for- } \\
\text { mação e eliminação dos riscos de acidente dos empre- } \\
\text { gados. Este construto é composto por ações voltadas } \\
\text { às condições de trabalho e a formação dos emprega- } \\
\text { dos e será denominado de: Ações Sociais de Proteção } \\
\text { e Formação dos Empregados (ASPFE) }\end{array}$} & \multirow[t]{2}{*}{$\begin{array}{l}\text { Verdolin e Alves (2005), } \\
\text { Balsadi (2007), Manzatto } \\
\text { et al. (2009) }\end{array}$} \\
\hline $\begin{array}{l}\text { SLA03 - Proporcionar treinamento e/ou formação continuada } \\
\text { aos empregados. }\end{array}$ & & \\
\hline
\end{tabular}

Fonte: Elaboração própria. 
Com a AFE foi possível identificar, em cada dimensão, os construtos que comporão o modelo estrutural de $1^{\underline{a}}$ e $2^{\underline{a}}$ ordens.

Para compor as variáveis do construto CSR, partiu-se do entendimento que as empresas promovem grande número de ações; no entanto, não necessariamente as consideram importantes. Ou, de forma contrária, consideram as ações importantes, porém, não as promovem.

Diante deste cenário, foram criadas variáveis denominadas de Grau de Conformidade (GC_EC, GC_EN e GC_SO), as quais têm por finalidade servir de parâmetro entre o Grau de Importância, que as empresas atribuíram para as ações socialmente responsáveis mencionadas no instrumento de pesquisa, e o número de ações efetivamente praticadas. Entende-se que considerar importante uma ação não garante sua execução, assim como a execução de uma determinada ação não necessariamente é resultado da importância atribuída a ela.

A apuração do GC_EC (dimensão econômica) se dá por meio da seguinte equação matemática:

$$
G C_{E C}=\frac{E C_{\text {RAESC }}+G I_{\text {MédiaEC }}}{2}
$$

em que: $G C_{E C}$ corresponde ao Grau de Conformidade da dimensão econômica; $E C_{R A_{E S C}}$ corresponde à proporção de respostas afirmativas, da dimensão econômica, na mesma escala atribuída ao grau de importância; e $G I_{\text {Média }_{E C}}$ corresponde à média do Grau de Importância da dimensão econômica.

Os mesmos procedimentos foram aplicados com os dados da dimensão ambiental (GC_EN) e da dimensão social (GC_SO).
Compostas todas as variáveis, promoveu-se a aplicação da MEE mediante a utilização do software SmartPLS, inciando pela análise da confiabilidade do modelo de mensuração e do modelo estrutural.

$\mathrm{Na}$ primeira análise (validade convergente), verificaram-se as cargas fatoriais identificadas entre as variáveis latentes e observadas de forma a manter os valores maiores que 0,7 .

Como resultado desse ajuste, foram excluídas as variáveis EC07 do construto de primeira ordem IET, EN05 do construto IAI, SLA01 do construto ASVA e SHR06 do construto ASPFE, o que refletiu nos valores adequados para AVE, os quais, além da Confiabilidade Composta, com resultados superiores a 0,7 e do alpha de Cronbach, estão representados na Tabela 4.

Conforme pode ser observado, os valores de AVE apresentaram resultados superiores a 0,50. A Confiabilidade Composta apresentou valores superiores a 0,7 , os quais são adequados.

Em relação ao alpha de Cronbach, observa-se que nem todos os resultados apresentaram valores superiores a 0,5, conforme sugerem algumas literaturas. Por outro lado, destaca-se que os valores dos construtos de segunda ordem, os quais em muitas pesquisas são considerados como referência principal, apresentaram os valores do alpha de Cronbach iguais a 0,6087 na dimensão econômica, 0,7017 na dimensão ambiental e 0,6819 na dimensão social; portanto, dentro dos limites recomendados.

Por outro lado, diante das possíveis ocorrências de valores baixos para o alpha de Cronbach, Almeida, Santos e Costa (2010) defendem que, apesar de a literatura científica que aborda este coeficiente ser ampla e abrangente, não existe um consenso entre os pesquisa-

Tabela 4. Análise de confiabilidade dos construtos

\begin{tabular}{lcccc}
\hline Construtos de 2 ${ }^{\mathbf{a}}$ Ordem & Construtos de 1a Ordem & Alpha Cronbach & Conf. Composta & AVE \\
\hline Dimensão Econômica & IEP & 0,4349 & 0,7788 & 0,6381 \\
& IES & 0,6568 & 0,8517 & 0,7420 \\
& IET & 0,3830 & 0,7641 & 0,6183 \\
\hline Dimensão Ambiental & IAE & 0,4024 & 0,7667 & 0,6232 \\
& IAI & 0,7302 & 0,8320 & 0,5537 \\
\hline Dimensão Social & ASCS & 0,6109 & 0,7936 & 0,5621 \\
& ASPFE & 0,5084 & 0,8014 & 0,6691 \\
& ASVA & 0,4547 & 0,7843 & 0,6457 \\
\hline
\end{tabular}

Fonte: Elaboração própria. 
dores acerca de sua interpretação. Embora alguns pesquisadores apontem um valor aceitável, existem outros que o utilizam sem fazer nenhuma menção a um valor mínimo.

Considerando que há mais de uma forma de validar o modelo, destaca-se que, em uma análise entre o alpha de Cronbach e a confiabilidade composta, a segunda é considerada mais adequada ao PLS, pois prioriza as variáveis de acordo com suas confiabilidades, enquanto o primeiro é muito sensível ao número de variáveis em cada construto (RINGLE, SILVA e BIDO, 2014).

A validade discriminante, demonstrada na Tabela 5 , foi obtida a partir da aplicação da raiz quadrada das AVEs, apresentando valores maiores que as correlações entre os construtos, conforme defendem Ringle, Silva e Bido (2014).

Para garantir a confiabilidade do modelo estrutural promoveu-se a análise dos coeficientes de determinação da variância $\left(R^{2}\right)$, da relevância preditiva ( $Q^{2}$ - Crossvalidated Redundancy), também conhecido como indicador de Stone-Geisser e o tamanho do efeito $\left({ }^{2}\right.$ - Crossvalidated Communality) ou indicador de Cohen.

Os resultados demonstraram que sete construtos $(\mathrm{ASPFE}=0,377, \mathrm{ASVA}=0,560, \mathrm{CSR}=0,374, \mathrm{IAE}=$ 0,453 , IES $=0,564$, IEP $=0,541$ e IET $=0,428$ ) apresentaram coeficientes de determinação moderados, enquanto que dois construtos (ASCS $=0,716$ e IAI $=$ 0,854 ) são considerados como substanciais.

Em relação à relevância preditiva $\left(Q^{2}\right)$ e ao tamanho do efeito ( $\left.f^{2}\right)$, Hair Junior et al. (2013) destacam que o primeiro possibilita avaliar quanto o modelo se aproxima do que se esperava dele, ou seja, a qualidade da predição do modelo ou acurácia do modelo ajustado, e tem como critério de adequação valores maiores que zero. Já o segundo demonstra quanto cada construto é útil para o ajuste do modelo. Como critério de análise, valores de 0,02 a 0,15 são considerados pequenos, de 0,16 a 0,35 são considerados médios e acima de 0,35 são considerados grandes.

Os resultados apresentaram valores de $Q^{2}$ maiores que zero e, em relação aos valores de $f^{2}$, um construto (IEP) é considerado médio e os demais são considerados de grande utilidade para o ajuste do modelo.

A fim de evitar contestações, registra-se que o indicador de Goodnesss-of-fit, que outrora fora apresentado como indicador adicional de confiabilidade do modelo em estudos, em que havia a aplicação do SmartPLS, não foi apurado nesta pesquisa. A decisão se apoia em estudos que consideraram o indicador como inócuo em seu poder estatístico para diferenciar a qualidade de um modelo estrutural (HAIR JUNIOR, et al., 2013; HENSELER e SARSTEDT, 2013).

Promovidos os testes estatísticos que avaliaram a confiabilidade do modelo de mensuração e do modelo estrutural, destaca-se que os construtos de $2^{-}$ordem (econômico, ambiental e social) explicam de forma moderada 37,4\% a variância de CSR. Essa conclusão deriva da análise do modelo estrutural em que o CSR apresentou $R^{2}$ igual a 0,374 .

A literatura não define a inviabilidade do modelo a partir do coeficiente de determinação $\left(R^{2}\right)$; no entanto, determina critérios que servem como parâmetros, sendo: até 0,19 são considerados fracos; de 0,33 até 0,66, moderados; e acima de 0,67, substanciais (CHIN, 1998; HENSELER, RINGLE e SINKOVICS, 2009).

Para facilitar a visualização do diagrama de caminhos, elaborou-se a Figura 1.

Tabela 5. Validade discriminante dos construtos de primeira ordem

\begin{tabular}{|c|c|c|c|c|c|c|c|c|c|}
\hline & ASCS & ASPFE & ASVA & CSR & IAE & IAI & IEP & IES & IET \\
\hline ASCS & 0,7498 & & & & & & & & \\
\hline ASPFE & 0,2663 & 0,8180 & & & & & & & \\
\hline ASVA & 0,4269 & 0,3053 & 0,8036 & & & & & & \\
\hline CSR & 0,6031 & 0,2400 & 0,3184 & 0,8030 & & & & & \\
\hline IAE & 0,4000 & 0,2689 & 0,3676 & 0,4646 & 0,7894 & & & & \\
\hline IAI & 0,4077 & 0,4644 & 0,3970 & 0,3617 & 0,3399 & 0,7441 & & & \\
\hline IEP & 0,4429 & 0,1729 & 0,3094 & 0,4503 & 0,1123 & 0,2755 & 0,7988 & & \\
\hline IEC & 0,4424 & 0,2135 & 0,2565 & 0,3427 & 0,3543 & 0,2212 & 0,2850 & 0,8614 & \\
\hline IET & 0,3211 & 0,2051 & 0,3497 & 0,2413 & 0,1665 & 0,3764 & 0,2808 & 0,2402 & 0,7863 \\
\hline
\end{tabular}

Fonte: Elaboração própria. 
Figura 1. Diagrama de caminhos: coeficientes $\beta$ e $t$ de student

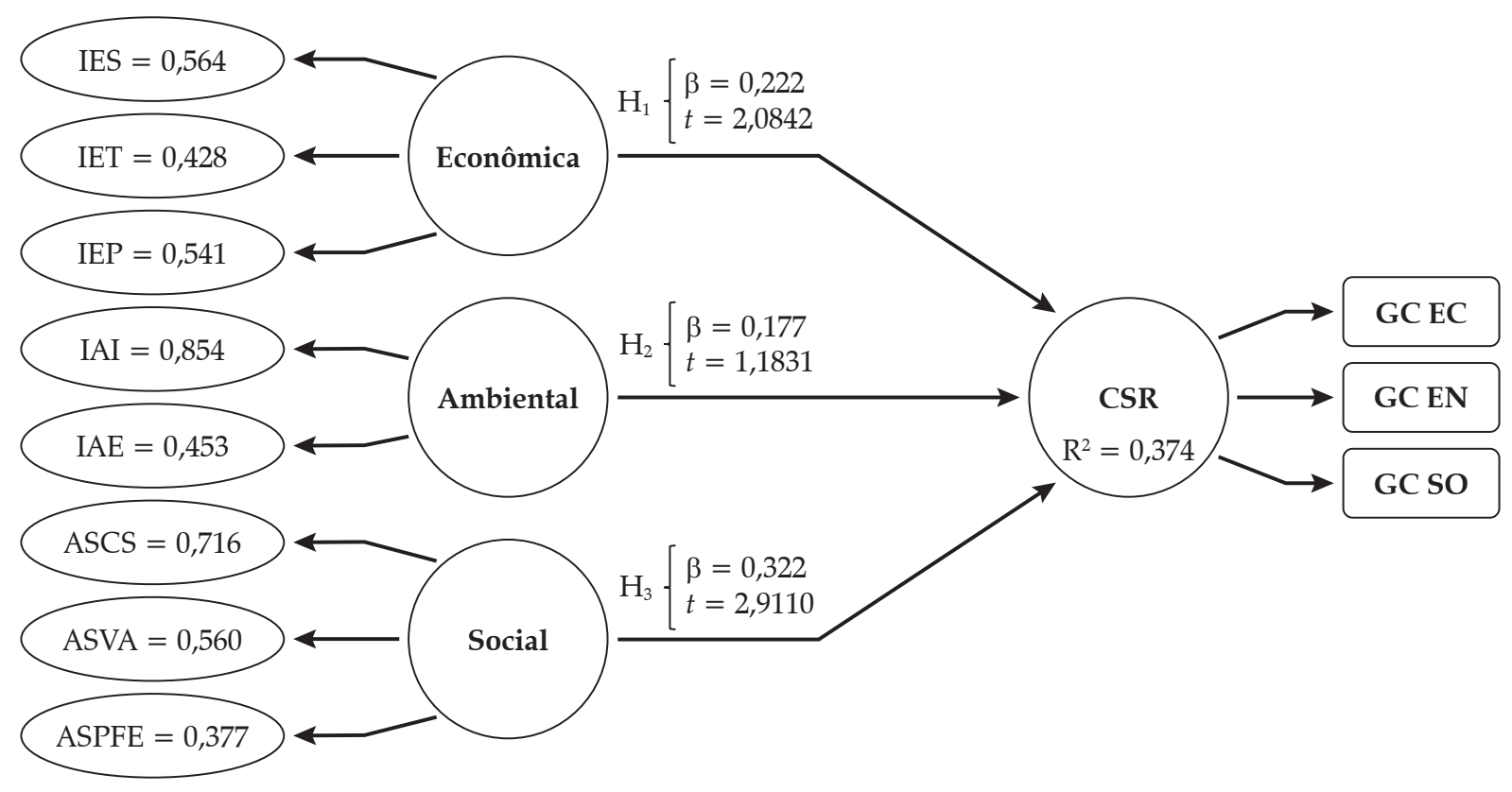

Fonte: Elaboração própria.

Para realizar o teste das hipóteses, partiu-se da identificação da robustez do modelo estrutural, utilizando a técnica bootstrapping, tendo como parâmetro de estimação a realização de 1.000 simulações do conjunto de dados. Como resultado da aplicação do bootstrapping obtém-se a significância das relações entre os construtos, a partir dos valores do $t$ de Student. Com este método é possível testar a relação causal entre dois construtos e verificar se eles são significantes ou não.

Em relação aos valores de $t$, utilizou-se como critério o nível de significância $5 \%$ ou 0,05 . De acordo com Hair Junior et al. (2005b), os valores de $t$ variam sua significância dentro dos seguintes critérios: acima de $1,65=10 \%$; acima de $1,96=5 \%$; e acima de $2,57=1 \%$ de nível de significância.
Os resultados demonstraram que as dimensões econômica e social exercem influência positiva no CSR, validando as duas hipóteses de pesquisa $\mathrm{H}_{1}$ e $\mathrm{H}_{3}$, enquanto que a dimensão ambiental, embora tenha apresentado um $\beta$ positivo, resultou numa relação não significante, refutando a hipótese $\mathrm{H}_{2}$.

A Tabela 6 apresenta a relação causal entre os construtos por meio dos coeficientes $\beta$, a significância dessa relação a partir do teste $t$ de Student e a validação das hipóteses.

É importante atentar para o fato de que o CSR, nesse estudo, não é reflexo da quantidade de ações promovidas e, sim, da percepção, apurada por meio da MEE, dos respondentes da pesquisa, os quais ocupam função estratégica nas agroindústrias cana-

Tabela 6. Relação causal e análise de hipóteses

\begin{tabular}{lcclcc}
\hline \multicolumn{1}{c}{ Relação causal } & $\beta$ & Valor $t$ & \multicolumn{1}{c}{ Hipóteses } & Validação \\
\hline Econômica $\rightarrow$ CSR & 0,222 & 2,0842 & $\begin{array}{l}\mathrm{H}_{1} \text { : A dimensão econômica influi positivamente o CSR das } \\
\text { agroindústrias canavieiras. }\end{array}$ & Confirmada \\
Ambiental $\rightarrow$ CSR & 0,177 & 1,1831 & $\begin{array}{l}\mathrm{H}_{2}: \text { A dimensão ambiental influi positivamente o CSR das } \\
\text { agroindústrias canavieiras. }\end{array}$ & Refutada \\
Social $\rightarrow$ CSR & 0,322 & 2,9110 & $\begin{array}{l}\mathrm{H}_{3} \text { : A dimensão social influi positivamente o CSR das agroin- } \\
\text { dústrias canavieiras. }\end{array}$ & Confirmada \\
\hline
\end{tabular}

Fonte: Elaboração própria. 
vieiras. É necessário entender que a MEE, por meio do SmartPLS, conforme defendem Hair Junior et al. (2013), identifica a importância relativa observada nos coeficientes gerados pelo modelo estrutural por meio da extração de estimativas dos relacionamentos diretos, indiretos e totais.

Portanto, quando o sistema promoveu a extração de estimativas dos relacionamentos diretos, indiretos e totais, identificou uma menor variância na dimensão ambiental em relação às demais dimensões, $o$ que refletiu na sua não significância, pois suas variáveis apresentam-se mais avançadas, tanto no grau de importância quanto na realização prática, em virtude da exigência imposta pela legislação, de políticas públicas como o ZAE Cana, dos acordos entre as empresas e o poder público e/ou em função de conscientização por parte dos gestores, frente aos possíveis impactos negativos causados pela atividade.

Esse resultado pode ser explicado a partir do fato que a atividade sucroalcooleira é bastante sensível às questões ambientais e, além de existir regulamentações que orientam os procedimentos a serem adotados antes, durante e depois do processo industrial, é comum os gestores agirem de forma preventiva.

Entre as duas dimensões que apresentaram resultado positivo e que confirmaram as hipóteses de pesquisa $\mathrm{H}_{1}$ e $\mathrm{H}_{3}$, a dimensão social demonstrou maior poder de influência no CSR, pois teve valor de $\beta=0,322$.

Dessa forma, confirma-se a Hipótese $4\left(\mathrm{H}_{4}\right.$ : A dimensão social influi direta e positivamente em maior proporção do que as dimensões econômica e ambiental no CSR das agroindústrias canavieiras).

Entre as possíveis explicações para este resultado, estão:

- a atividade sucroalcooleira tem um histórico relacionamento com a ocorrência de trabalho infantil, análogo a escravo, impacto na saúde e qualidade de vida dos trabalhadores, baixa remuneração, carência de organização sindical, condições precárias de moradia e de alimentação (ALESSI e NAVARRO, 1997; MUNDO NETO, 2009; MACIEL et al., 2011);

- a preocupação com o impacto social que está sendo gerado com a gradativa substituição da mão de obra do corte da cana-de-açúcar, pela colheita mecanizada, tende a gerar a redução de, aproximadamente, 480 mil postos de trabalho em todo o Brasil (SUSPENSÃO..., 2014);

- o posicionamento dos participantes da pesquisa em depoimentos ocorridos durante as entrevistas demonstraram haver uma constante preocupação, pois consideram que desde a colonização do País a atividade esteve ligada à mão de obra de escravos, gerando um entendimento que parece ter se perpetuado ao longo das gerações, e isso gera insatisfação, pois existem atividades que promovem mais externalidades negativas e, mesmo assim, o setor sucroalcooleiro é mais visado e negativamente avaliado pela opinião pública. Defendem, também, que as agroindústrias cumprem integralmente a legislação, conscientes dos riscos associados ao não cumprimento; que, por mais que atividade seja importante para a segurança alimentar, produção energética, geração de empregos e divisas, há uma cultura de olhar somente o lado negativo, o qual as empresas não negam que possam ocorrer; porém, em proporções muito menores do que as imaginadas; $\mathrm{e}$

- o entendimento revelado pela pesquisa de que a Responsabilidade Social está relacionada intimamente com as atividades desenvolvidas pelos empregados, atribuindo ao setor de pessoal/recursos humanos a função de implantar e acompanhar o desenvolvimento das ações que minimizem os impactos negativos para os empregados e, adicionalmente, para a sociedade. Esse entendimento é possivelmente justificado a partir da afirmação de Rosa (2010) e de Melo Neto e Froes (2001), sendo que a primeira defende que os profissionais que atuam no setor de pessoal/recursos humanos agem como parceiros, colaborando constantemente nas ações de Responsabilidade Social. O setor assume papel estratégico na formação de equipes sintonizadas com o CSR e dão suporte ao público interno. Já os segundos autores destacam que os empregados e seus dependentes desempenham papéis dentro e fora da empresa como agentes sociais, assumindo o perfil de promotores e difusores da Responsabilidade Social. 


\section{Considerações finais}

O estudo, a partir do embasamento teórico, demonstrou que as agroindústrias canavieiras estão em estágios diferentes em se tratado de CSR e que demonstram preocupação com a sustentabilidade de suas operações, buscando minimizar o seu impacto socioambiental.

Diante dessas constatações, elaborou-se, a partir do suporte teórico que aborda o tripé da Responsabilidade Social, o instrumento de coleta de dados dando origem aos construtos que compuseram o diagrama de caminhos.

Após garantir a confiabilidade do modelo de mensuração, do modelo estrutural e aplicar a MEE, observou-se que as dimensões econômica e social exercem influência positiva no CSR, enquanto que a dimensão ambiental, embora tenha apresentado um coeficiente $\beta$ positivo, mostrou-se estatisticamente não significante.

É importante reafirmar que o CSR é resultado da percepção, apurada por meio da MEE, dos respondentes da pesquisa. A MEE, por meio do SmartPLS, conforme defendem Hair Junior et al. (2013), é uma metodologia que identifica a importância relativa observada nos coeficientes gerados pelo modelo estrutural através da extração de estimativas dos relacionamentos diretos, indiretos e totais, confrontando o grau de importância com a realização prática, ou seja, avaliando a percepção dos respondentes em relação ao equilíbrio entre achar importante e praticar (Grau de Conformidade), como forma de explicar o CSR.

Os resultados do modelo estrutural também demonstraram que, entre as dimensões que exibiram relação positiva e significante, a dimensão social apresentou o maior poder de influência no CSR. Esta maior influência no CSR das agroindústrias canavieiras pode ser derivada de: a) questões históricas, que marcaram o desenvolvimento do setor sucroalcooleiro; b) características da atividade, relacionadas aos impactos positivos e negativos aos empregados e à sociedade; c) organização administrativa e/ou o entendimento dos respondentes em relação à necessidade de gerir o impacto social e a imagem negativa atrelada à atividade; d) entendimento de que o setor de pessoal/ recursos humanos seja o mais indicado para implantar e acompanhar o desenvolvimento de ações socialmente responsáveis.
Desta forma, esta pesquisa defende a tese que, de acordo com o entendimento dos gestores das agroindústrias canavieiras no Brasil e com base na aplicação da MEE, existe influência positiva das dimensões econômica, ambiental e social no CSR. Não obstante, quando comparadas as três dimensões, devido ao fato de que a atividade sucroalcooleira é bastante sensível às questões ambientais, além de existirem regulamentações que orientam os procedimentos a serem adotados antes, durante e depois do processo industrial, estatisticamente a dimensão ambiental mostrou-se não significante. Por outro lado, a dimensão social, por questões históricas, características da atividade e organização administrativa, mostrou maior poder de influência no CSR.

\section{Referências}

ALESSI, N. P. e NAVARRO, V. L. Saúde e trabalho rural: o caso dos trabalhadores da cultura canavieira na região de Ribeirão Preto, São Paulo, Brasil. Caderno Saúde Pública, Rio de Janeiro, v. 13 (Supl. 2), p. 111-121, 1997.

ALMEIDA, D., SANTOS, A. D. e COSTA, A. F. B. Aplicação do coeficiente alfa de cronbach nos resultados de um questionário para avaliação de desempenho da saúde pública. In: XXX Encontro Nacional de Engenharia De Produção, 2010, São Carlos. Anais..., São Carlos, 12 a 15 de outubro de 2010.

ANDRADE, J. M. F. e DINIZ, K. M. Impactos ambientais da agroindústria da cana-de-açúcar: subsídios para a gestão. 2007. 131 f. Monografia (Especialização em Gerenciamento Ambiental) - Escola Superior de Agricultura Luiz de Queiroz - ESALQ/ USP. Piracicaba. 2007.

ASHLEY, P. A. Ética e responsabilidade social nos negócios. São Paulo: Saraiva, 2002.

AUGUSTO, A., TAKAHASHI, L. Y. e SACHUK, M. Y. A influência da inovação tecnológica na competitividade e nas relações de trabalho em usinas de açúcar e álcool paranaenses. Organizações Rurais \& Agroindustriais, Lavras, v. 14, n. 1, p. 1-14, 2012.

AVRAM, E. e AVASILCAI, S. Business performance measurement in relation to corporate social responsibility: a conceptual Model Development. Procedia - Social and Behavioral Sciences, v. 109, p. 11421146, 2014. 
BABBIE, E. Métodos de pesquisas de survey. Belo Horizonte: UFMG, 1999.

BALSADI, O. V. Mercado de trabalho assalariado na cultura da cana-de-açúcar no Brasil no período 19922004. Informações Econômicas, São Paulo, v. 37, n. 2, fev. 2007.

BRAGATO, I. R. et al. Produção de açúcar e álcool vs. responsabilidade social corporativa: as ações desenvolvidas pelas usinas de cana-de-açúcar frente às externalidades negativas. Gestão $\mathcal{E}$ Produção, São Carlos, v. 15, n. 1, p. 89-100, jan./abr. 2009.

CARVALHO, E. R., VIAN, C. E. F. e BRAUN, M. B. S. A inserção da responsabilidade social no setor sucroalcooleiro: motivações e benefícios do comportamento socialmente responsável no setor. Informe Gepec, Toledo, v. 15, n. 2, p. 155-190, jul./dez. 2011.

CARVALHO, L. R. F.etal. Demonstração da responsabilidade social. Porto Alegre: CRC/RS, 2009.

CASSOL, A. et al. A administração estratégica do capital intelectual: um modelo baseado na capacidade absortiva para potencializar inovação. Revista IberoAmericana de Estratégia - RIAE, v. 15, n. 1, p. 27-43, jan./ mar. 2016.

CHADDAD, F. R. UNICA: Challenges to Deliver Sustainability in the Brazilian Sugarcane Industry. International Food and Agribusiness Management Association (IFAMA), v. 13, n. 4, p. 173-192, 2010.

CHAGAS, R. D. S. B. Análise da estrutura agroindustrial canavieira a partir dos processos de diversificação industrial e inovações verificados no período de 2000 à 2010. 2014. 147 f. Dissertação (Mestrado em Políticas Públicas) Programa de Pós-graduação em Políticas Públicas, Estratégias e Desenvolvimento - Instituto de Economia da Universidade Federal do Rio de Janeiro. Rio de Janeiro. 2014.

CHIN, W. W. The partial least squares approach to structural equation modeling. In: MARCOULIDES, G. A. Modern methods for business research. Mahwah, NJ: Lawrence Erlbaum Associates, 1998. p. 295-358.

CHIZZOTTI, A. Pesquisa em ciências humanas e sociais. São Paulo: Cortez, 2001.

CHURCHIL JUNIOR, G. A. Marketing research: methodological foundations. 7. ed. New York: InterThomson Publishing, 1999.

COLLARES, C. F. O que é e pra que serve a modelagem de equações estruturais? Traduzindo conceitos $e$ espinhos, 2011. Disponivel em: < http://carloscollares. blogspot.com.br/2011/08/o-que-e-e-pra-que-servemodelagem-de.html>. Acesso em: 21 jun. 2016.

COSTELlO, A. B. e OSBORNE, J. W. Best practices in exploratory factor analysis: four recommendations for getting the most from your analysis. Practical ASsessment Research E Evaluation, v. 10, n. 7, p. 13-24, July 2005.

DIAS, R. Responsabilidade social: fundamentos e gestão. São Paulo: Atlas, 2012.

ELIA NETO, A. Aspectos da legislação ambiental para o setor da cana-de-açúcar. In: MACEDO, I. D. C. A energia da cana-de-açúcar - doze estudos sobre a agroindústria da cana-de-açúcar no Brasil e a sua sustentabilidade. São Paulo: Berlendis \& Vertecchia: UNICA - União da Agroindústria Canavieira do Estado de São Paulo, 2005. p. 75-78.

EON, F. O que é responsabilidade social? Revista ResponsabilidadeSocial.com, 2015. Disponível em: < http://www.responsabilidadesocial.com/o-que-eresponsabilidade-social/>. Acesso em: 15 maio 2016.

ETHOS. Indicadores ethos de responsabilidade social empresarial. São Paulo: Instituto Ethos, 2000.

. Guia de elaboração de elaboração de relatório e balanço social anual de responsabilidade social empresarial. Instituto Ethos de Empresas e Responsailidade Social, São Paulo, 2001.

O Balanço Social e a Comunicação da Empresa com a sociedade. Instituto Ethos de Empresas e Responsabilidade Social, São Paulo, jun. 2007.

. Glossário - Indicadores. Indicadores Ethos para negócios sustentáveis e responsáveis, 2013. Disponível em: < < ltp://www3.ethos.org.br/wp-content/ uploads/2013/09/Gloss \% C3\% A1rio-IndicadoresEthos-V2013-09-022.pdf>. Acesso em: 14 maio 2016.

FÁVERO, L. P. et al. Análise de dados: modelagem multivariada para tomada de decisões. Rio de Janeiro: Elsevier, 2009.

FILGUEIRAS, M. L. Recuperação Judicial: entra ruim, sai pior. exame.abril.com, 2016. Disponível em: < http:// exame.abril.com.br/revista-exame/edicoes/1110/ noticias/entra-ruim-sai-pior-como-e-recuperacaojudicial-na-pratica >. Acesso em: 14 abr. 2016.

FONTES, M. A. Empresas e investimentos sociais. São Paulo: Atlas, 2001.

GRAJEW, O. Visão estratégica da sustentabilidade social. Revista Opiniões, 2006. Disponível em: < http:// sucroenergetico.revistaopinioes.com.br/revista/ 
detalhes/10-visao-estrategica-da-sustentabilidadesocial/>. Acesso em: 25 jun. 2016.

GRI. Global Reporting Initiative. G4 Sustainability Reporting Guidelines - Reporting principles and standard disclosures, Amsterdam, 2013a.

G4 Sustainability Reporting Guidelines Implementation Manual, Amsterdam, $2013 \mathrm{~b}$.

. Elaboração de relatórios de sustentabilidade: o que é um relatório de sustentabilidade?, 2015a. Disponível em: $\quad<$ https://www.globalreporting.org/languages/ Portuguesebrazil/Pages/Elabora\%C3\%A7\%C3\%A3ode-relat \% C3\% B3rios-de-sustentabilidade.aspx > . Acesso em: 29 maio 2016.

. History, 2015b. Disponível em: <https://www. globalreporting.org/information/about-gri/what-isGRI/Pages/default.aspx> . Acesso em: 05 jun. 2016.

HAIR JUNIOR, J. F. et al. Análise multivariada de dados. 5. ed. Porto Alegre: Bookman, 2005a.

. et al. Fundamentos de métodos de pesquisa em administração. Porto Alegre: Bookman, 2005b.

. et al. A primer on partial least squares structural equation modeling (PLS-SEM). Thousand Oaks: Sage, 2013.

. et al. Partial least squares structural equation modeling (PLS-SEM): An emerging tool in business research. European Business Review, v. 26, n. 2, p. 106121, 2014a.

.et al. A primer on partial least squares structural equation modeling (PLS-SEM). Washington DC: Sage, 2014b.

HAIR, J. F., RINGLE, C. M. e SARSTEDT, M. PLS-SEM: Indeed a Silver Bullet. Journal of Marketing Theory and Practice, v. 19, n. 2, p. 139-151, Spring 2011.

HENSELER, J., RINGLE, C. M. e SINKOVICS, R. R. The use of partial least squares path modeling in international marketing. Advances inInternationalMarketing, v. 20, p. 277-319, 2009.

. e SARSTEDT, M. Goodness-of-fit indices for partial least squares path modeling. Computational Statistics, v. 28, n. 2, p. 565-580, abr. 2013.

HOLME, L. eWATTS, R. Corporate social responsability. World Business Council for Sustainable Development, Geneva, 1999.

JUNQUEIRA, P., STERCHILE, S. P. W. e SHIKIDA, F. A. Mudança institucional e o impacto no padrão tecnológico: o caso da mecanização da colheita de cana-de-açúcar no Paraná. Organizações Rurais \& Agroindustriais, Lavras, v. 11, n. 1, p. 87-105, 2009.
KARKOTLI, G. Responsabilidade social empresarial. 2. ed. Petrópolis, RJ: Vozes, 2007.

LAKATOS, E. M. e MARCONI, M. A. Fundamentos metodologia científica. 4. ed. São Paulo: Atlas, 2001.

MACEDO, I. C. Síntese. In: MACEDO, I. C. A energia da cana-de-açúcar - doze estudos sobre a agroindústria da cana-de-açúcar no Brasil e a sua sustentabilidade. São Paulo: Berlendis \& Vertecchia: UNICA - União da Agroindústria Canavieira do Estado de São Paulo, 2005. p. 27-38.

MACIEL, M. R. et al. Trabalho e saúde: o caso dos trabalhadores temporários da indústria canavieira em Lagoa da Prata, Minas Gerais Brasil. Interfacehs - Revista de Saúde, Meio Ambiente e Sustentabilidade, São Paulo, v. 6, n. 3, p. 43-57, 2011.

MALHOTRA, N. K. Pesquisa de marketing: uma orientação aplicada. 4. ed. Porto Alegre: Artmed, 2008.

MANZATTO, V. et al. Zoneamento agroecológico da cana-deaçúcar - expandir a produção, preservar a vida, garantir o futuro. Rio de Janeiro: Embrapa Solos, 2009. 55 p.

MAPA - Ministério da Agricultura, Pecuária e Abastecimento. Culturas: cana de açúcar, 2015. Disponível em: < http://www.agricultura.gov.br/vegetal/ culturas/cana-de-acucar> . Acesso em: 13 abr. 2016.

MARIANO, J. O destino está praticamente selado para as 85 usinas em recuperação judicial no Brasil. NovaCana.com, 2016. Disponível em: <https://www. novacana.com/n/industria/usinas/destino-selado-85usinas-recuperacao-judicial-brasil-280116/>. Acesso em: 15 fev. 2016.

MARIANO, R. P. Elementos principais dos diferentes modelos propostos de Balanço Social. Pensar Contábil, Rio de Janeiro, n. 9, ago./out. 2000.

MARQUES, V.D.L.eALLEDIFILHO,C. Responsabilidade social: conceitos e práticas: construíndo o caminho para a sustentabilidade nas organizações. São Paulo: Atlas, 2012.

MELO NETO, P.D. eFROES, C. Gestão da responsabilidade social corporativa: o caso brasileiro. Rio de Janeiro: Qualitymark, 2001.

MORALES, G. M.-A. Partial Least Squares (PLS) Methods: Origins, Evolution, and Application to Social Sciences. Communications in Statistics - Theory and Methods, 2011. Disponível em: < http://eprints.ucm. es/13208/> . Acesso em: 15 ago. 2016.

MUNDO NETO, M. De sucroalcooleiro a sucroenergético: a construção de um campo organizacional. In: $33^{\circ}$ Encontro Anual da ANPOCS, 
Caxambu, 26a 30 Outubro 2009. Disponivel em: <http:// portal.anpocs.org/portal/index.php?option $=\mathrm{com}$ docman\&task $=$ doc_view\&gid $=2164 \& I t e m i d=229>$. Acesso em: 15 abril 2016.

NOVAES, E. N. Responsabilidade Social e abertura de capitais: uma descrição dentro do complexo agroindustrial canavieiro do Brasil. 2009. $154 \mathrm{f}$. Dissertação (Mestrado em Engenharia de Produção) Programa de Engenharia de Produção da Universidade Federal de São Carlos. São Carlos. 2009.

PENEDO, A. S. T. Limites e possibilidades do balanço social. 2011. 188 f. Tese (Doutorado em Engenharia de Produção) - Programa de Pós-graduação em Engenharia de Produção, da Universidade Federal de São Carlos. São Carlos, SP. 2011.

RAMOS, P. A evolução da agroindústria canavieira e os mercados de açúcar e de álcool carburante no Brasil: a necessidade de planejamento e controle. In: XLVI CONGRESSO DA SOCIEDADE BRASILEIRA DE ECONOMIA, ADMINISTRAÇÃO E SOCIOLOGIA RURAL, 2008, Rio Branco. Anais..., Rio Branco/Acre, 2008.

RINGLE, C. M., SILVA, D. D. e BIDO, D. Modelagem de equações estruturais com utilização do smartpls. REMark - Revista Brasileira de Marketing, v. 13, n. 2, p. 56-73, maio 2014.

RODRIGUES, D. e ORTIZ, L. Em direção a sustentabilidade da produção de etanol de cana de açúcar no Brasil. São Paulo: Amigos da Terra Brasil \& Vitae Civilis, 2006.

ROSA, S. O papel da área de RH na Responsabilidade Social Empresarial. RH - Responsabilidade Social, 2010. Disponivel em: <http://www.rh.com.br/Portal/ Responsabilidade_Social/Artigo/6642/o-papel-da-areade-rh-na-responsabilidade-social-empresarial.html> . Acesso em: 11 out. 2016.

SAPCANA - Sistema de Acompanhamento da Produção Canavieira. Download da base completa de cadastro de instituições, 2015. Disponível em: $<$ http://sistemasweb.agricultura.gov.br/sapcana/ downloadBaseCompletaInstituicao.action?sgJAASAp licacaoPrincipal=sapcana $>$. Acesso em: 27 ago. 2015.

SHIKIDA, P. F. A. e SOUZA, E. C. Agroindústria canavieira e crescimento econômico local. Revista de
Economia e Sociologia Rural, Piracicaba, v. 47, n. 3, p. 569600, jul./set. 2009.

SILVA, A. C. D. e GARCIA, R. A. M. Teoria dos stakeholders e responsabilidade social: algumas considerações para as organizações contemporâneas. 2011. 17 f. Artigo (Trabalho de Conclusão de Curso) - Pós-graduação latu sensu à distância em MBA Executivo em Gestão Empresarial - Convênio Universidade Católica Dom Bosco (UCDB)/Portal da Educaão. Campo Grande/MS. 2011.

STONER, J. A. F. e FREEMAN, E. R. Administração. 5. ed. Rio de Janeiro: Prentice-Hell do Brasil, 1990.

SUSPENSÃO de queimadas preocupa trabalhadores de canaviais. G1, Jornal Nacional, 2014. Disponível em: <http://g1.globo.com/jornal-nacional/noticia/2014/03/ suspensao-de-queimadas-preocupa-trabalhadores-decanaviais.html >. Acesso em: 16 abr. 2016.

SZMRECSÁNYI, T. O planejamento da agroindústria canavieira do Brasil: 1930-1975. São Paulo: HUCITEC, Universidade Estadual de Campinas, 1979.

TABACHNICK, B. e FIDELL, L. S. Using multivariate statistic. 4. ed. Needham: Allyn \& Bacon, 2001.

TENÓRIO, F. G. (Org.). Responsabilidade social empresarial: teoria e prática. 2. ed. Rio de Janeiro: FGV, 2006.

TONETO JUNIOR, R. e LIBONI, L. B. Evoilução recente do mercado de trabalho da cana-de-açúcar no Brasil (1995-2006). Organizações Rurais \& Agroindustriais, Lavras, v. 10, n. 3, p. 455-474, 2008.

VERDOLIN, D. R. e ALVES, A. F. Responsabilidade Social: perspectivas para o agronegócio. Organizações Rurais \& Agroindustriais, Lavras, v. 7, n. 1, p. 103-113, 2005.

VIAN, C. E. F. Agroindústria canavieira: estratégias competitivas e modernização. Campinas: Átomo, 2003.

WISSMANN, M. A. Responsabilidade social nas agroindústrias canavieiras no Brasil. 2017, 303 f. (Tese de Doutorado) - Programa de Pós-graduação em Desenvolvimento Regional e Agronegócio da Universidade Estadual do Oeste do Paraná. Toledo. 2017. 
Apêndice A. Questionário.

\begin{tabular}{|c|c|c|}
\hline Dimensão Econômica & Dimensão Ambiental & Dimensão Social \\
\hline $\begin{array}{l}\text { EC01 - Proporcionar aos empregados o } \\
\text { recebimento de valores referente à Par- } \\
\text { ticipação nos Lucros e Resultados (PLR). }\end{array}$ & $\begin{array}{l}\text { EN01 - Possuir controle do uso de mate- } \\
\text { riais renováveis e não renováveis ou pro- } \\
\text { venientes de reciclagem. }\end{array}$ & $\begin{array}{l}\text { SLA01 - Promover ações para evitar a } \\
\text { rotatividade (turnover) de empregados, } \\
\text { dentro e/ou fora do ambiente de trabalho } \\
\text { (Ex.: programas de saúde, ambiente de } \\
\text { lazer, atividades recreativas, atividades } \\
\text { educativas e/ou recreativas com os fami- } \\
\text { liares, outras). }\end{array}$ \\
\hline $\begin{array}{l}\text { EC02 - Coparticipar ou promover o paga- } \\
\text { mento integral por parte da empresa, de } \\
\text { plano de aposentadoria complementar } \\
\text { aos empregados. }\end{array}$ & $\begin{array}{l}\text { EN02 - Adotar sistema de cogeração de } \\
\text { energia. }\end{array}$ & $\begin{array}{l}\text { SLA02 - Adotar ações evitando riscos de } \\
\text { acidentes e de doenças relacionadas à } \\
\text { ocupação dos empregados. }\end{array}$ \\
\hline \multirow{2}{*}{$\begin{array}{l}\text { EC03 - Destinar recursos financeiros e/ } \\
\text { ou materiais, por parte da empresa (de } \\
\text { forma voluntária, além das obrigações } \\
\text { legais), visando evitar e/ou reduzir pos- } \\
\text { síveis impactos ambientais (Ex.: poluição, } \\
\text { reciclagem e reutilização, outros). }\end{array}$} & $\begin{array}{l}\text { EN03 - Fazer uso, na atividade da empre- } \\
\text { sa, de água reciclada ou reutilizada. }\end{array}$ & $\begin{array}{l}\text { SLA03 - Proporcionar treinamento e/ou } \\
\text { formação continuada aos empregados. }\end{array}$ \\
\hline & $\begin{array}{l}\text { EN04 - Possuir áreas de proteção ambien- } \\
\text { tal ou reflorestamento. }\end{array}$ & $\begin{array}{l}\text { SLA04 - Adotar critérios de igualdade em } \\
\text { relação à etnia, idade ou gênero na defini- } \\
\text { ção de salários e/ou cargos de chefia. }\end{array}$ \\
\hline $\begin{array}{l}\text { EC04 - Promover investimentos, com } \\
\text { recursos próprios, em infraestrutura e/ } \\
\text { ou serviços oferecidos, que beneficiam a } \\
\text { sociedade. }\end{array}$ & $\begin{array}{l}\text { EN05 - Desenvolver ações que visem à re- } \\
\text { dução da emissão de gases poluentes no } \\
\text { processo de industrialização. }\end{array}$ & $\begin{array}{l}\text { SLA05 - Promover acompanhamento das } \\
\text { práticas trabalhistas adotadas pelos FOR- } \\
\text { NECEDORES. }\end{array}$ \\
\hline $\begin{array}{l}\text { EC05 - Destinar recursos financeiros no } \\
\text { intuito de promover ações que geram } \\
\text { impacto econômico indireto como: ações } \\
\text { que visem auxiliar pessoas de baixa ren- } \\
\text { da, estímulo à implantação de instituições } \\
\text { de ensino (investimentos em educação), } \\
\text { entre outros. }\end{array}$ & $\begin{array}{l}\text { EN06 - Acomodar e destinar os resíduos } \\
\text { gerados pelo processo de industrialização } \\
\text { (vinhaça, torta de filtro e outros), de for- } \\
\text { ma a minimizar os impactos ambientais } \\
\text { negativos. }\end{array}$ & $\begin{array}{l}\text { SHR06 - Dar liberdade aos emprega- } \\
\text { dos para participarem de associações de } \\
\text { entidades de classe, reconhecendo sua } \\
\text { função (Ex.: Sindicatos) (Obs.: o não re- } \\
\text { conhecimento da função desqualifica a } \\
\text { liberdade). }\end{array}$ \\
\hline \multirow[t]{2}{*}{$\begin{array}{l}\text { EC06 - Promover investimentos em tec- } \\
\text { nologias (automação, ergonomia, equipa- } \\
\text { mentos de proteção individual, outra), vi- } \\
\text { sando melhorar as condições de trabalho } \\
\text { dos empregados. }\end{array}$} & \multirow[t]{2}{*}{$\begin{array}{l}\text { EN07 - Exigir dos FORNECEDORES um } \\
\text { comportamento ambientalmente correto: } \\
\text { prevenção, mitigação e/ou correção de } \\
\text { possíveis impactos ambientais negativos. }\end{array}$} & $\begin{array}{l}\text { SHR07 - Promover ações que visem cons- } \\
\text { cientizar e eliminar o trabalho infantil, } \\
\text { forçado ou análogo ao escravo na cadeia } \\
\text { produtiva. }\end{array}$ \\
\hline & & $\begin{array}{l}\text { SSO08 - Adotar procedimentos para evi- } \\
\text { tar e combater a corrupção nas atividades } \\
\text { que a empresa está envolvida. }\end{array}$ \\
\hline \multirow[t]{2}{*}{$\begin{array}{l}\text { EC07 - Promover investimento visando } \\
\text { à colheita mecanizada de cana-de-açúcar. }\end{array}$} & \multirow[t]{2}{*}{$\begin{array}{l}\text { EN08 - Possuir um setor responsável para } \\
\text { receber e dar encaminhamento às queixas } \\
\text { e reclamações relacionadas aos possíveis } \\
\text { impactos ambientais causados pela em- } \\
\text { presa. }\end{array}$} & $\begin{array}{l}\text { SSO09 - Verificar, na seleção de FORNE- } \\
\text { CEDORES, se estes promovem ações so- } \\
\text { cialmente responsáveis em benefício da } \\
\text { sociedade. }\end{array}$ \\
\hline & & $\begin{array}{l}\text { SPR10 - Possuir um canal de comunica- } \\
\text { ção (site, serviço de atendimento ao con- } \\
\text { sumidor, outro), pelo qual disponibiliza }\end{array}$ \\
\hline
\end{tabular}

Legenda: EC - Dimensão Econômica (Economic); EN - Dimensão Ambiental (Environmental); SLA - Dimensão Social (LA - Labor Practices and Decent Work);SHR - Dimensão Social (HR - Human Rights); SSO - Dimensão Social (SO - Society); SPR - Dimensão Social (PR - Product Responsibility).

Todo o conteúdo deste periódico, exceto onde estiver identificado, está licenciado sob uma Licença Creative Commons (cc by 4.0). 